\title{
Complete genome sequence of the hyperthermophilic chemolithoautotroph Pyrolobus fumarii type strain $\left(1 \mathrm{~A}^{\mathrm{T}}\right)$
}

\author{
lain Anderson ${ }^{1}$, Markus Göker ${ }^{2}$, Matt Nolan ${ }^{1}$, Susan Lucas ${ }^{1}$, Nancy Hammon ${ }^{1}$, Shweta \\ Deshpande', Jan-Fang Cheng ${ }^{1}$, Roxanne Tapia ${ }^{1,3}$, Cliff Han ${ }^{1,3}$, Lynne Goodwin ${ }^{1,3}$, Sam \\ Pitluck ${ }^{1}$, Marcel Huntemann'1, Konstantinos Liolios ${ }^{1}$, Natalia Ivanova ${ }^{1}$, Ioanna Pagani ${ }^{1}$, \\ Konstantinos Mavromatis ${ }^{1}$, Galina Ovchinikova ${ }^{1}$, Amrita Pati ${ }^{1}$, Amy Chen ${ }^{4}$, Krishna Pala- \\ niappan $^{4}$, Miriam Land ${ }^{1,5}$, Loren Hauser ${ }^{1,5}$, Evelyne-Marie Brambilla ${ }^{2}$, Harald Huber ${ }^{6}$, Montri \\ Yasawong ${ }^{7}$, Manfred Rohde ${ }^{7}$, Stefan Spring ${ }^{2}$, Birte Abt $^{2}$, Johannes Sikorski ${ }^{2}$, Reinhard Wirth ${ }^{6}$, \\ John C. Detter ${ }^{1,3}$, Tanja Woyke ${ }^{1}$, James Bristow ${ }^{1}$, Jonathan A. Eisen ${ }^{1,8}$, Victor Markowitz ${ }^{4}$, \\ Philip Hugenholtz ${ }^{1,9}$, Nikos C. Kyrpides ${ }^{1}$, Hans-Peter Klenk ${ }^{2}$, and Alla Lapidus ${ }^{1 *}$ \\ ${ }^{1}$ DOE Joint Genome Institute, Walnut Creek, California, USA \\ ${ }^{2}$ DSMZ - German Collection of Microorganisms and Cell Cultures GmbH, Braunschweig, \\ Germany \\ ${ }^{3}$ Los Alamos National Laboratory, Bioscience Division, Los Alamos, New Mexico, USA \\ ${ }^{4}$ Biological Data Management and Technology Center, Lawrence Berkeley National \\ Laboratory, Berkeley, California, USA \\ ${ }^{5}$ Oak Ridge National Laboratory, Oak Ridge, Tennessee, USA \\ ${ }^{6}$ University of Regensburg, Microbiology - Archaeenzentrum, Regensburg, Germany \\ ${ }^{7}$ HZI - Helmholtz Centre for Infection Research, Braunschweig, Germany \\ ${ }^{8}$ University of California Davis Genome Center, Davis, California, USA \\ ${ }^{9}$ Australian Centre for Ecogenomics, School of Chemistry and Molecular Biosciences, The \\ University of Queensland, Brisbane, Australia \\ *Corresponding author: Alla Lapidus
}

Keywords: hyperthermophile, chemolithoautotroph, facultative microaerophilic, non-motile, hydrothermal solfataric vents, black smoker, Pyrodictiaceae, GEBA

Pyrolobus fumarii Blöchl et al. 1997 is the type species of the genus Pyrolobus, which be-
longs to the crenarchaeal family Pyrodictiaceae. The species is a facultatively microaerophilic
non-motile crenarchaeon. It is of interest because of its isolated phylogenetic location in the
tree of life and because it is a hyperthermophilic chemolithoautotroph known as the primary
producer of organic matter at deep-sea hydrothermal vents. P. fumarii exhibits currently the
highest optimal growth temperature of all life forms on earth $\left(106^{\circ} \mathrm{C}\right)$. This is the first com-
pleted genome sequence of a member of the genus Pyrolobus to be published and only the
second genome sequence from a member of the family Pyrodictiaceae. Although Diversa
Corporation announced the completion of sequencing of the P. fumarii genome on Septem-
ber 25,2001 , this sequence was never released to the public. The $1,843,267$ bp long genome
with its 1,986 protein-coding and 52 RNA genes is a part of the Genomic Encyclopedia of
Bacteria and Archaea project.

\section{Introduction}

Strain $1 \mathrm{~A}^{\mathrm{T}}$ (= DSM 11204) is the type strain of the species Pyrolobus fumarii, which is the type and only species of its genus Pyrolobus [1]. The generic name derives from the Greek word pyr meaning fire and the Greek word lobos meaning lobe, referring to fire lobe. The species epithet is derived from the Latin word fumarii meaning of the chimney, referring to its black smoker biotope [1]. Strain $1 \mathrm{~A}^{\mathrm{T}}$ was isolated from a black smoker wall, TAG site, Mid Atlantic Ridge [2], effectively published in
1997 [1] and validly published in 1999 [3]. It is thus far the most heat-tolerant, and also most heatrequiring of all validly named prokaryotic species. $P$. fumarii appears to be the primary producer of organic material in such deep-sea hydrothermal vent habitats [1]. At the time of its discovery, P. fumarii extended the upper temperature limit for life to $113^{\circ} \mathrm{C}$ [1]. A more recent report on a not yet validly named and incompletely characterized iron-reducing archaeon, known only as 'Strain 
$121^{\prime}$ appears to extend the upper growth temperature to $121^{\circ} \mathrm{C}$, which is well within standard autoclaving temperatures [4]. Here we present a summary classification and a set of features for $P$. fumarii strain $1 \mathrm{~A}^{\mathrm{T}}$, together with the description of the complete genomic sequencing and annotation.

\section{Classification and features}

The single genomic $16 \mathrm{~S}$ rRNA sequence of strain $1 \mathrm{~A}^{\mathrm{T}}$ was compared using NCBI BLAST [5] under default settings (e.g., considering only the high-scoring segment pairs (HSPs) from the best 250 hits) with the most recent release of the Greengenes database [6] and the relative frequencies of taxa and keywords (reduced to their stem [7]) were determined, weighted by BLAST scores. The most frequently occurring genera were Aeropyrum (18.1\%), Desulfurococcus (11.1\%), Ignicoccus (9.8\%), Vulcanisaeta (7.8\%) and Staphylothermus (7.0\%) (68 hits in total). Regarding the single hit to sequences from members of the species, the average identity within HSPs was $99.0 \%$, whereas the average coverage by HSPs was $46.1 \%$. Among all other species, the one yielding the highest score was Hyperthermus butylicus (NC_008818), which corresponded to an identity of $99.2 \%$ and an HSP coverage of $46.1 \%$. (Note that the Greengenes database uses the INSDC I= EMBL/NCBI/DDBJ) annotation, which is not an authoritative source for nomenclature or classification). The highest-scoring environmental sequence was AB293243 ('Microbial structures around area Southern Mariana Trough hydrothermal sulfide structure clone Pcsc3A31'), which showed an identity of $96.9 \%$ and an HSP coverage of $44.7 \%$. The most frequently occurring keywords within the labels of environmental samples which yielded hits were 'spring' (12.0\%), 'hot' (7.5\%), 'microbi' (7.0\%), 'nation, park, yellowston' (6.2\%) and 'geochem' (3.7\%) (181 hits in total). Environmental samples which yielded hits of a higher score than the highest scoring species were not found. These keywords reflect some of the ecological features and properties reported for strain $1 \mathrm{~A}^{\mathrm{T}}$ in the original description [1].

Figure 1 shows the phylogenetic neighborhood of $P$. fumarii in a $16 \mathrm{~S}$ rRNA based tree. The sequence of the single $16 \mathrm{~S}$ rRNA gene copy in the genome does not differ from the previously published $16 \mathrm{~S}$ rRNA sequence (X99555), which contains eleven ambiguous base calls.
Cells of strain $1 \mathrm{~A}^{\mathrm{T}}$ are regularly to irregularly lobed cocci with a diameter of approximately $0.7-2.5 \mu \mathrm{m}$ (Figure 2) [1]. The strain is non-motile, non-sporeforming and facultatively microaerophilic (Table 1). Strain $1 \mathrm{~A}^{\mathrm{T}}$ has a temperature range for growth between $90^{\circ} \mathrm{C}$ and $113^{\circ} \mathrm{C}$ (optimum $106^{\circ} \mathrm{C}$ ) and is unable to propagate at a temperature of $90^{\circ} \mathrm{C}$ or below $[1,32]$. Exponentially growing cultures of $P$. fumarii survive even autoclaving at $121^{\circ} \mathrm{C}$ for one hour [1]. At the optimum growth temperature, doubling time of $P$. fumarii is 60 minutes [1]. The $\mathrm{pH}$ range for growth is 4.0-6.5, with an optimum pH of 5.5 [1]. The strain forms white colonies (1 $\mathrm{mm}$ in diameter) on Gelrite-containing media [1]. Like in Hyperthermus, no cell-to-cell network is formed and the S-layer exhibits a central depression, most likely a pore $[1,32]$. Such networks of extracellular tubules appear to be characteristic for members of the genus Pyrodictium. $P$. fumarii strain $1 \mathrm{~A}^{\mathrm{T}}$ is able to grow on medium that contains $1 \%-4 \% \mathrm{NaCl}$, with an optimum salinity at $1.7 \%$ [1]. The organism uses $\mathrm{CO}_{2}$ as the single carbon source and $\mathrm{H}_{2}$ as the obligate electron donor [1]. The organism is tolerant to high pressure condition $(25,000 \mathrm{kPa})$ [1]. Under anaerobic and microaerophilic conditions, $P$. fumarii is obligately chemolithoautotroph and is able to oxidize $\mathrm{H}_{2}$ coupled with $\mathrm{NO}_{3}{ }^{-}, \mathrm{S}_{2} \mathrm{O}_{3}{ }^{2-}$ and $\mathrm{O}_{2}$ as electron acceptors [1]. Nitrate is reduced to ammonia [1]. Organic compounds do not stimulate the growth of $P$. fumarii [1]. P. fumarii does not grow in media containing acetate, pyruvate, glucose, starch and elementary sulfur [1]. A highly selective enrichment method for P. fumarii in comparison to other members of the family Pyrodictiaceae is based on the use of nitrate as the sole electron acceptor [32]. Crude extracts of $P$. fumarii strain $1 \mathrm{~A}^{\mathrm{T}}$ cells show a strong cross-reaction with antibodies prepared against the thermosome of Pyrodictium occultum [32], which could suggest highly similar chaperonin protein complexes. Furthermore, a membrane-associated hydrogenase with an optimum reaction temperature of $119^{\circ} \mathrm{C}$ is found in cells grown on molecular hydrogen and nitrate [32]. Interestingly, succinyl-CoA reduction in $P$. fumarii is not NAD(P)H-dependent, but requires reduced methyl viologen as in Ignicoccus hospitalis [33,34]. In the RNA of hyperthermophiles, posttranscriptional modification has been identified as a leading mechanism of structure stabilization [35-39]. Twentysix modified nucleosides of $P$. fumarii are detected, 11 of which are methylated in ribose [38]. P. fumarii exhibits a novel RNA nucleosides characterized as 1,2'-O-dimethylguanosine $\left(\mathrm{m}^{1} \mathrm{Gm}\right)$ [38]. 


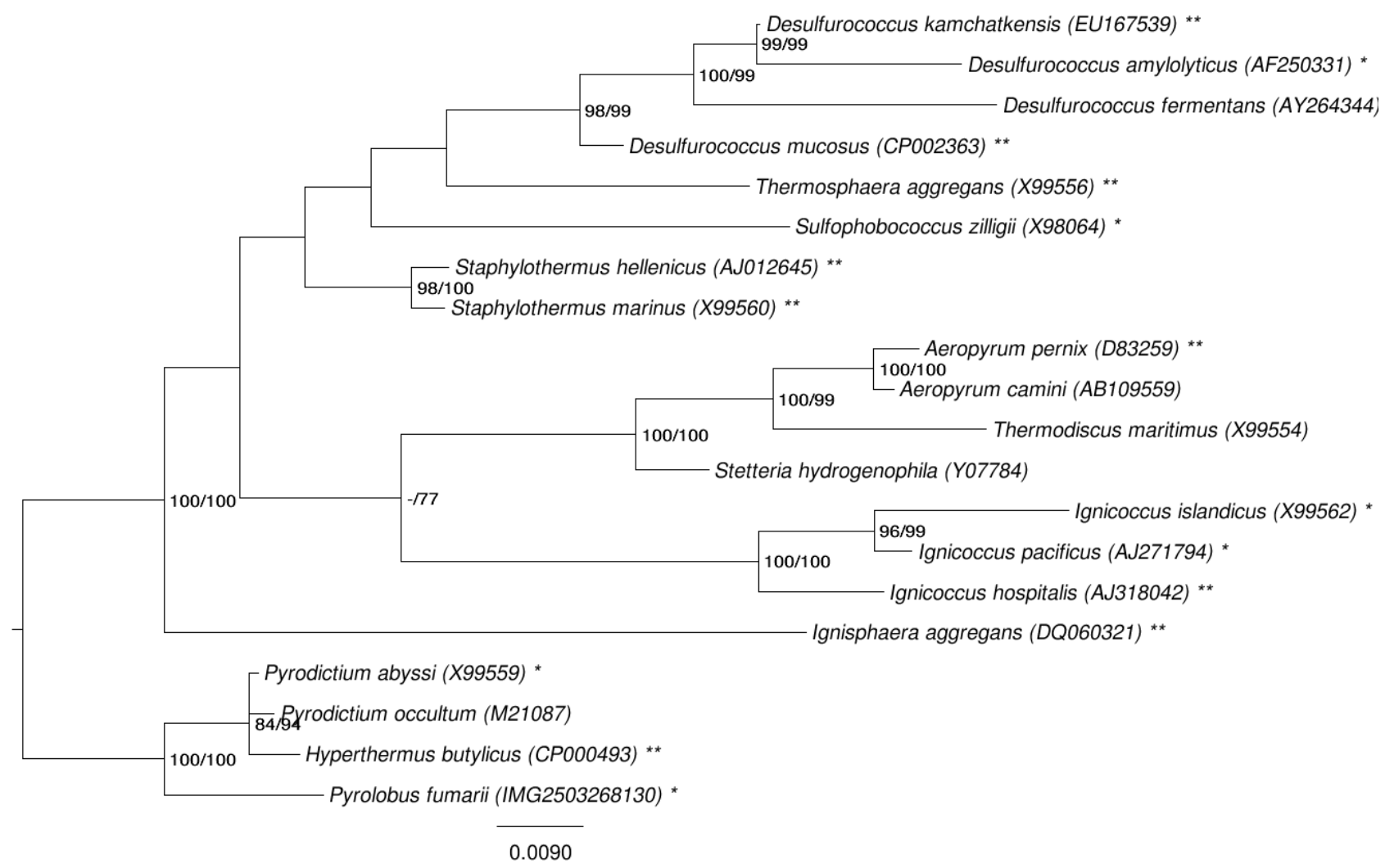

Figure 1. Phylogenetic tree highlighting the position of $P$. fumarii relative to the type strains of the other species within the order Desulfurococcales. The tree was inferred from 1,333 aligned characters [8,9] of the 16S rRNA gene sequence under the maximum likelihood $(\mathrm{ML})$ criterion [10]. Rooting was done initially using the midpoint method [11] and then checked for its agreement with the current classification (Table 1). The branches are scaled in terms of the expected number of substitutions per site. Numbers adjacent to the branches are support values from 1,000 ML bootstrap replicates [12] (left) and from 1,000 maximum parsimony bootstrap replicates [13] (right) if larger than $60 \%$. Lineages with type strain genome sequencing projects registered in GOLD [14] are labeled with one asterisk, those also listed as 'Complete and Published' with two asterisks (see [15-21], and CP002051 for Staphylothermus hellenicus).

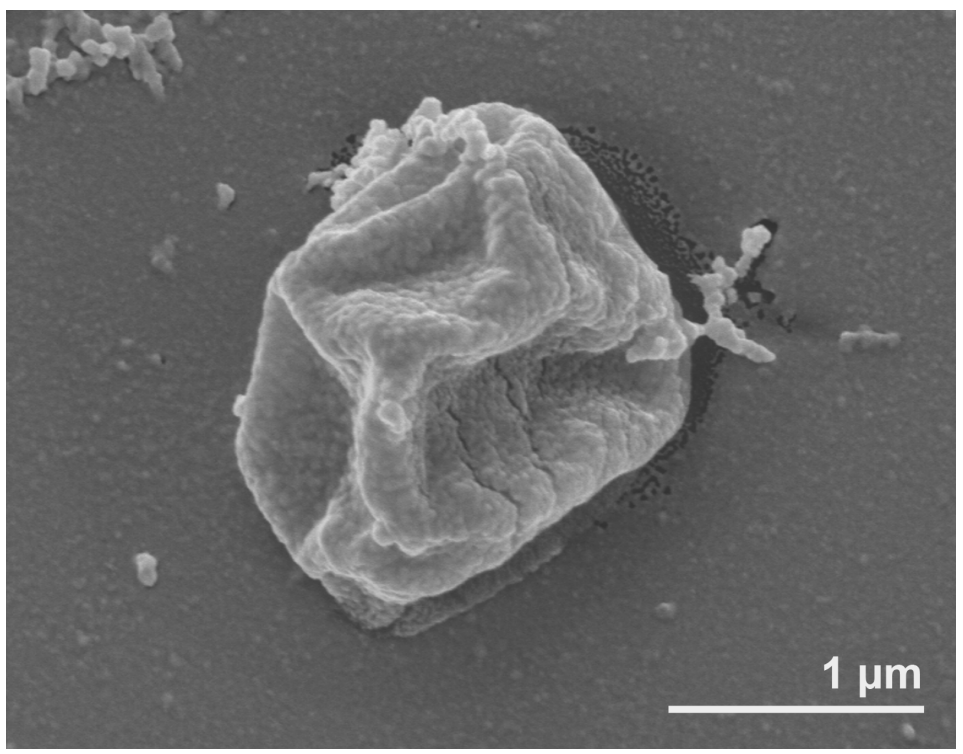

Figure 2. Scanning electron micrograph of $P$. fumarii $1 A^{\top}$ 


\section{Chemotaxonomy}

The S-layer of strain $1 \mathrm{~A}^{\mathrm{T}}$ exhibits p4 symmetry with a lattice of $18.5 \mathrm{~nm}$ that encloses a $40-\mathrm{nm}$ wide 'quasi-periplasmic space' [1]. The major core lipids of strain $1 \mathrm{~A}^{\mathrm{T}}$ are uncyclized glycerol-dialkylglycerol-tetraether (GDGT) and traces of 2,3-di-Ophytanyl-sn-glycerol (diether) [1]. Cells of strain $1 \mathrm{~A}^{\mathrm{T}}$ do not contain $\mathrm{C}_{20} \mathrm{C}_{25}$ diethers and cyclized GDGT [1]. Non-hydrolyzed lipids contain a main spot on TLC staining blue (instead of violet) by anisaldehyde [1]. The major organic solute of strain $1 \mathrm{~A}^{\mathrm{T}}$ is di-myo-inositol phosphate (DIP) [40].
DIP and its derivatives are consistently associated with the heat stress response and therefore, are probably involved in the thermoprotection [15]. UDP-sugars are present in cells of strain $1 \mathrm{~A}^{\mathrm{T}}$ [40]. The structures of the two major UDP-sugars are identified as UDP- $\alpha$-GlcNAc3NAc and UDP- $\alpha$ GlcNAc3NAc- $(4 \leftarrow 1)-\beta$-GlcpNAc3NAc [40]. UDPsugars are intermediates of an $N$-linked glycosylation pathway of strain $1 \mathrm{~A}^{\mathrm{T}}$ [40]. Strain $1 \mathrm{~A}^{\mathrm{T}}$ performs a posttranscriptional modification of transfer RNA [38].

Table 1. Classification and general features of $P$. fumarii $1 \mathrm{~A}^{\top}$ according to the MIGS recommendations [22] and the NamesforLife database [23].

\begin{tabular}{|c|c|c|c|}
\hline MIGS ID & Property & Term & Evidence code \\
\hline & & Domain Archaea & TAS [24] \\
\hline & & Phylum Crenarchaeota & TAS [25] \\
\hline & & Class Thermoprotei & TAS $[26,27]$ \\
\hline & & Order Desulfurococcales & TAS $[26,28]$ \\
\hline & & Family Pyrodictiaceae & TAS [29] \\
\hline & & Genus Pyrolobus & TAS $[1,3]$ \\
\hline & & Species Pyrolobus fumarii & TAS $[1,3]$ \\
\hline & Current classification & Type strain $1 \mathrm{~A}$ & TAS [1] \\
\hline & Gram stain & "negative" & TAS [1] \\
\hline & Cell shape & $\begin{array}{l}\text { regularly to irregularly lobed cocci, occurring } \\
\text { singly and in short chains }\end{array}$ & TAS [1] \\
\hline & Motility & none & TAS [1] \\
\hline & Sporulation & none & TAS [1] \\
\hline & Temperature range & $90-113^{\circ} \mathrm{C}$ & TAS [1] \\
\hline & Optimum temperature & $106^{\circ} \mathrm{C}$ & TAS [1] \\
\hline & Salinity & $1 \%-4 \%(\mathrm{w} / \mathrm{v}) \mathrm{NaCl}$ (optimum 1.7\%) & TAS [1] \\
\hline \multirow[t]{3}{*}{ MIGS-22 } & Oxygen requirement & facultatively microaerophilic & TAS [1] \\
\hline & Carbon source & $\mathrm{CO}_{2}$ & TAS [1] \\
\hline & Energy metabolism & chemolithoautotrophic & TAS [1] \\
\hline MIGS-6 & Habitat & abyssal deep-sea hydrothermal systems & TAS [1] \\
\hline MIGS-15 & Biotic relationship & free-living & NAS \\
\hline \multirow[t]{3}{*}{ MIGS-14 } & Pathogenicity & none & NAS \\
\hline & Biosafety level & 1 & TAS [30] \\
\hline & Isolation & rock samples from wall of a black smoker & TAS [1] \\
\hline MIGS-4 & Geographic location & Mid Atlantic Ridge & TAS [1] \\
\hline MIGS-5 & Sample collection time & 1993 & NAS \\
\hline MIGS-4.1 & Latitude & 26 & TAS [1] \\
\hline MIGS-4.2 & Longitude & -45 & TAS [1] \\
\hline MIGS-4.3 & Depth & $3,650 \mathrm{~m}$ & TAS [1] \\
\hline MIGS-4.4 & Altitude & $-3,650 m$ & TAS [1] \\
\hline
\end{tabular}

Evidence codes - IDA: Inferred from Direct Assay (first time in publication); TAS: Traceable Author Statement (i.e., a direct report exists in the literature); NAS: Non-traceable Author Statement (i.e., not directly observed for the living, isolated sample, but based on a generally accepted property for the species, or anecdotal evidence). These evidence codes are from of the Gene Ontology project [31]. If the evidence code is IDA, the property should have been directly observed by one of the authors or an expert mentioned in the acknowledgements 


\section{Genome sequencing and annotation}

\section{Genome project history}

This organism was selected for sequencing on the basis of its phylogenetic position [41], and is part of the Genomic Encyclopedia of Bacteria and Archaea project [42]. The genome project is deposited in the Genome On Line Database [14] and the complete genome sequence is deposited in GenBank. Sequencing, finishing and annotation were performed by the DOE Joint Genome Institute (JGI). A summary of the project information is shown in Table 2.

Table 2. Genome sequencing project information

\begin{tabular}{lll}
\hline MIGS ID & Property & Term \\
\hline MIGS-31 & Finishing quality & Finished \\
MIGS-28 & Libraries used & Three genomic libraries: one 454 pyrosequence standard li- \\
brary, one 454 PE library (6 kb insert size), one Illumina library \\
MIGS-29 & Sequencing platforms & Illumina GAii, 454 GS FLX Titanium \\
MIGS-31.2 & Sequencing coverage & $1,753.4 \times$ Illumina; $60.4 \times$ pyrosequence \\
MIGS-30 & Assemblers & Newbler version 2.5, Velvet 0.7.63, phrap SPS - 4.24 \\
MIGS-32 & Gene calling method & Prodigal 1.4, GenePRIMP \\
& INSDC ID & CP002838 \\
& Genbank Date of Release & pending \\
& GOLD ID & Gi02934 \\
& NCBI project ID & 48579 \\
& Database: IMG-GEBA & 2505679005 \\
MIGS-13 & Source material identifier & DSM 11204 \\
& Project relevance & Tree of Life, GEBA \\
\hline
\end{tabular}

\section{Growth conditions and DNA isolation}

P. fumarii $1 \mathrm{~A}^{\mathrm{T}}$, DSM 11204, was grown anaerobically in DSMZ medium 792 (Pyrolobus fumarii medium) [43] at $103^{\circ} \mathrm{C}$. DNA was isolated from $0.5-1$ g of cell paste using Qiagen Genomic 500 DNA Kit (Qiagen, Hilden, Germany) following the standard protocol as recommended by the manufacturer.

\section{Genome sequencing and assembly}

The genome was sequenced using a combination of Illumina and 454 sequencing platforms. All general aspects of library construction and sequencing can be found at the JGI website [44]. Pyrosequencing reads were assembled using the Newbler assembler (Roche). The initial Newbler assembly consisting of ten contigs in one scaffold was converted into a phrap [45] assembly by making fake reads from the consensus, to collect the read pairs in the 454 paired end library. Illumina sequencing data $(3,232.0 \mathrm{Mb})$ was assembled with Velvet [46] and the consensus sequences were shredded into $1.5 \mathrm{~kb}$ overlapped fake reads and assembled together with the 454 data. The 454 draft assembly was based on $79.2 \mathrm{Mb}$ 454 draft data and all of the 454 paired end data. Newbler parameters are -consed -a 50 -1 350 -g -m - $\mathrm{ml}$ 20. The Phred/Phrap/Consed software package [45] was used for sequence assembly and quality assessment in the subsequent finishing process. After the shotgun stage, reads were assembled with parallel phrap (High Performance Software, LLC). Possible mis-assemblies were corrected with gapResolution [44], Dupfinisher, or sequencing cloned bridging PCR fragments with subcloning or transposon bombing (Epicentre Biotechnologies, Madison, WI) [47]. Gaps between contigs were closed by editing in Consed, by PCR and by Bubble PCR primer walks (J.-F. Chang, unpublished). A total of 12 additional reactions were necessary to close gaps and to raise the quality of the finished sequence. Illumina reads were also used to correct potential base errors and increase consensus quality using a software Polisher developed at JGI [48]. The error rate of the completed genome sequence is less than 1 in 100,000 . Together, the combination of the Illumina and 454 sequencing platforms provided 1,813.8 $\times$ coverage of the genome. The final assembly contained 431,902 pyrosequence and 44,889,308 Illumina reads. 


\section{Genome annotation}

Genes were identified using Prodigal [49] as part of the Oak Ridge National Laboratory genome annotation pipeline, followed by a round of manual curation using the JGI GenePRIMP pipeline [50]. The predicted CDSs were translated and used to search the National Center for Biotechnology Information (NCBI) non-redundant database, UniProt, TIGRFam, Pfam, PRIAM, KEGG, COG, and InterPro databases. Additional gene prediction analysis and functional annotation was performed within the Integrated Microbial Genomes - Expert Review (IMG-ER) platform [51].

\section{Genome properties}

The genome consists of a 1,843,267 bp long chromosome with a $54.9 \% \mathrm{G}+\mathrm{C}$ content (Table 3 and Figure 3). Of the 2,038 genes predicted, 1,986 were protein-coding genes, and 52 RNAs; 19 pseudogenes were also identified. The majority of the protein-coding genes (54.9\%) were assigned a putative function while the remaining ones were annotated as hypothetical proteins. The distribution of genes into COGs functional categories is presented in Table 4.

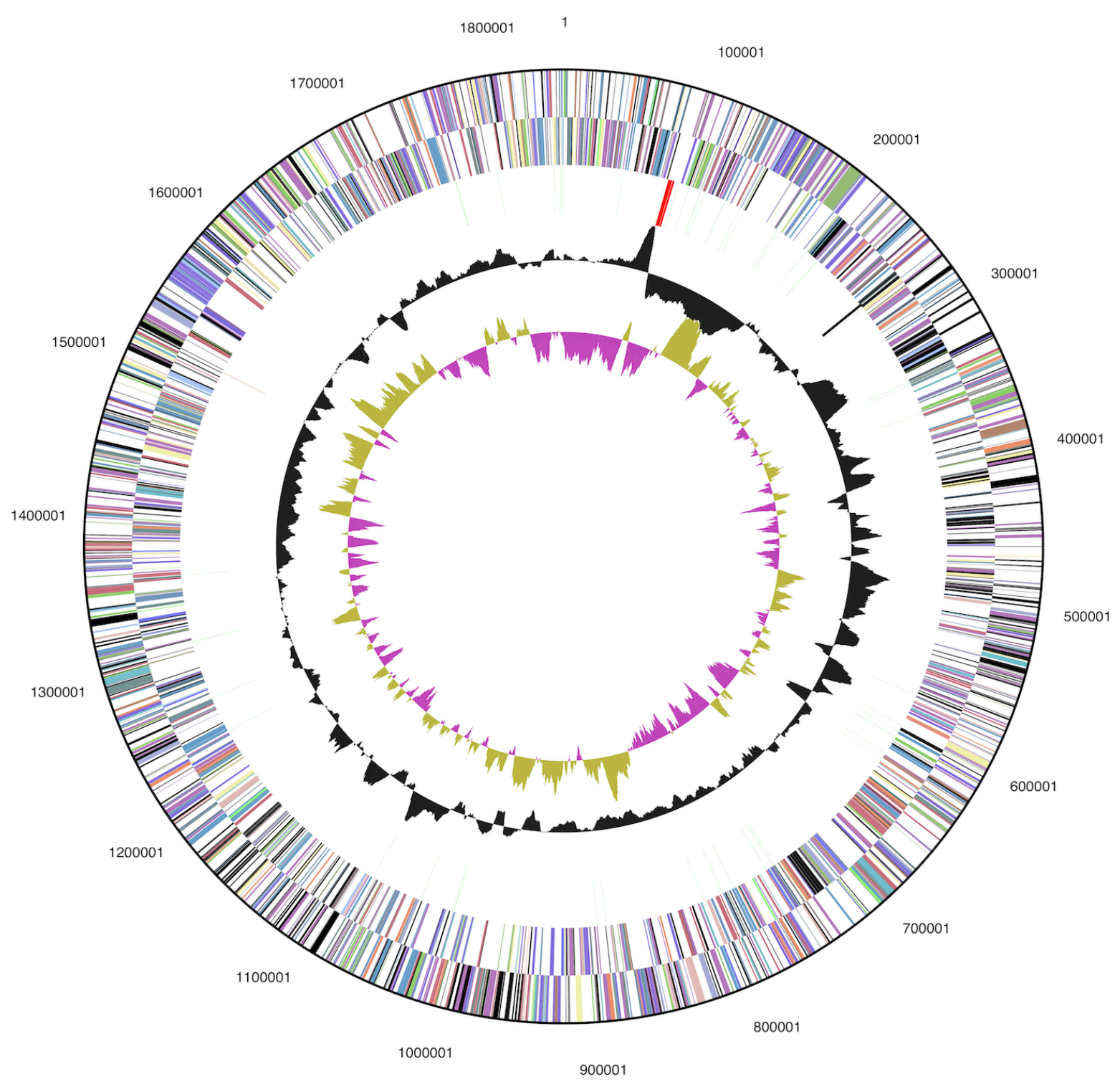

Figure 3. Graphical circular map of the genome. From outside to the center: Genes on forward strand (color by COG categories), Genes on reverse strand (color by COG categories), RNA genes (tRNAs green, rRNAs red, other RNAs black), GC content, GC skew. 
Table 3. Genome Statistics

\begin{tabular}{lrr}
\hline Attribute & Value & \% of Total \\
\hline Genome size (bp) & $1,843,267$ & $100.00 \%$ \\
DNA coding region (bp) & $1,616,680$ & $87.71 \%$ \\
DNA G+C content (bp) & $1,012,030$ & $54.90 \%$ \\
Number of replicons & 1 & \\
Extrachromosomal elements & 0 & \\
Total genes & 2,038 & $100.00 \%$ \\
RNA genes & 52 & $2.55 \%$ \\
rRNA operons & 1 & \\
Protein-coding genes & 1,986 & $97.45 \%$ \\
Pseudo genes & 19 & $0.93 \%$ \\
Genes with function prediction & 1,119 & $54.91 \%$ \\
Genes in paralog clusters & 82 & $4.02 \%$ \\
Genes assigned to COGs & 1,325 & $65.01 \%$ \\
Genes assigned Pfam domains & 1,283 & $62.95 \%$ \\
Genes with signal peptides & 207 & $10.16 \%$ \\
Genes with transmembrane helices & 368 & $18.06 \%$ \\
CRISPR repeats & 0 & \\
\hline
\end{tabular}

Table 4. Number of genes associated with the general COG functional categories

\begin{tabular}{lrrl}
\hline Code & value & \%age & Description \\
\hline J & 178 & 12.5 & Translation, ribosomal structure and biogenesis \\
A & 2 & 0.1 & RNA processing and modification \\
K & 84 & 5.9 & Transcription \\
L & 72 & 5.1 & Replication, recombination and repair \\
B & 3 & 0.2 & Chromatin structure and dynamics \\
D & 16 & 1.1 & Cell cycle control, cell division, chromosome partitioning \\
Y & 0 & 0.0 & Nuclear structure \\
V & 10 & 0.7 & Defense mechanisms \\
T & 31 & 2.2 & Signal transduction mechanisms \\
M & 27 & 1.9 & Cell wall/membrane/envelope biogenesis \\
N & 10 & 0.7 & Cell motility \\
Z & 0 & 0.0 & Cytoskeleton \\
W & 0 & 0.0 & Extracellular structures \\
U & 19 & 1.3 & Intracellular trafficking and secretion \\
O & 60 & 4.2 & Posttranslational modification, protein turnover, chaperones \\
C & 97 & 6.8 & Energy production and conversion \\
G & 36 & 2.5 & Carbohydrate transport and metabolism \\
E & 120 & 8.5 & Amino acid transport and metabolism \\
F & 51 & 3.6 & Nucleotide transport and metabolism \\
H & 99 & 7.0 & Coenzyme transport and metabolism \\
I & 18 & 1.3 & Lipid transport and metabolism \\
P & 54 & 3.8 & Inorganic ion transport and metabolism \\
Q & 11 & 0.8 & Secondary metabolites biosynthesis, transport and catabolism \\
R & 260 & 18.1 & General function prediction only \\
S & 162 & 11.4 & Function unknown \\
- & 713 & 35.0 & Not in COGs \\
\hline
\end{tabular}




\section{Insights from the genome sequence}

Table 5 shows the whole-genome distances between $P$. fumarii and the other type strains within the order Desulfurococcales [15-21] as calculated using the genome-to-genome distance calculator [52-54]. As expected, the distances to the only other member of the family Pyrodictiaceae, $H$. butylicus, are lower than those to the members of the Desulfurococcaceae. This does not hold for formula 2, which is affected by saturation: if only HSPs of more strongly conserved genes are obtained, these contain, on average, a higher proportion of identical base pairs [52].

Table 5.

\begin{tabular}{|c|c|c|}
\hline \multirow{2}{*}{$\begin{array}{l}\text { Reference genome } \\
\text { Aeropyrum pernix BA000002 }\end{array}$} & \multicolumn{2}{|c|}{ Formula Distance } \\
\hline & 1 & 0.9809 \\
\hline & 2 & 0.1414 \\
\hline & 3 & 0.9836 \\
\hline \multirow[t]{3}{*}{ Desulfurococcus kamchatkensis СР001140 } & 1 & 0.9889 \\
\hline & 2 & 0.1194 \\
\hline & 3 & 0.9903 \\
\hline \multirow[t]{3}{*}{ Desulfurococcus mucosus CP002363 } & 1 & 0.9836 \\
\hline & 2 & 0.1321 \\
\hline & 3 & 0.9857 \\
\hline \multirow[t]{3}{*}{ Hyperthermus butylicus CP000493 } & 1 & 0.9514 \\
\hline & 2 & 0.1632 \\
\hline & 3 & 0.9593 \\
\hline \multirow[t]{3}{*}{ Ignicoccus hospitalis CP000816 } & 1 & 0.9777 \\
\hline & 2 & 0.1410 \\
\hline & 3 & 0.9808 \\
\hline \multirow[t]{3}{*}{ Ignisphaera aggregans СР002098 } & 1 & 0.9940 \\
\hline & 2 & 0.1062 \\
\hline & 3 & 0.9946 \\
\hline \multirow[t]{3}{*}{ Staphylothermus hellenicus CP002051 } & 1 & 0.9909 \\
\hline & 2 & 0.1167 \\
\hline & 3 & 0.9920 \\
\hline \multirow[t]{3}{*}{ Staphylothermus marinus CP000575 } & 1 & 0.9916 \\
\hline & 2 & 0.1121 \\
\hline & 3 & 0.9925 \\
\hline \multirow[t]{3}{*}{ Thermosphaera aggregans СР001939 } & 1 & 0.9883 \\
\hline & 2 & 0.1215 \\
\hline & 3 & 0.9897 \\
\hline
\end{tabular}

Genome-to-genome distances between $P$. fumarii and the genomes of other type strains within the order. The formulas are: 1 - HSP length/total length; 2- identities/HSP length;

3 - identities/total length $[52,53]$. 
Figure 4 shows a neighbor-joining tree inferred with PAUP* [13] from the logarithmized version of distance 3. The tree differs from the 16S rRNA-based tree (Figure 1) regarding the position of Ignisphaera aggregans, which is placed as sister group of all other Desulfurococcaceae by the 16S rRNA, but of Staphylothermus in the whole-genome tree.

The fraction of shared genes in the genomes of $P$. fumarii, its closest neighbor $H$. butylicus, and as an outgroup I. aggregans (see Figure 1) is shown in a Venn diagram (Figure 5). The numbers of pairwise shared genes were calculated with the phylogenetic profiler function of the IMG-ER platform [51]. The homologous genes within the genomes were detected with a maximum E-value of $10^{-5}$ and a minimum identity of 30\%. 719 genes (39\%) are shared by P. fumarii, I. aggregans and H. butylicus. P. fumarii and $H$. butylicus share 410 genes, whereas I. aggregans shares only 89 and 177 with $H$. butylicus and $P$. fumarii, respectively, corroborating with the larger phylogenetic distance. With only 398 genes (25\%) $H$. butylicus contains the smallest fraction of unique genes (and the smallest genome, 1,616 genes), while I. aggregans has not only the largest genome $(1,992$ genes), but also the highest fraction of unique genes (51\%) in this set of organisms.

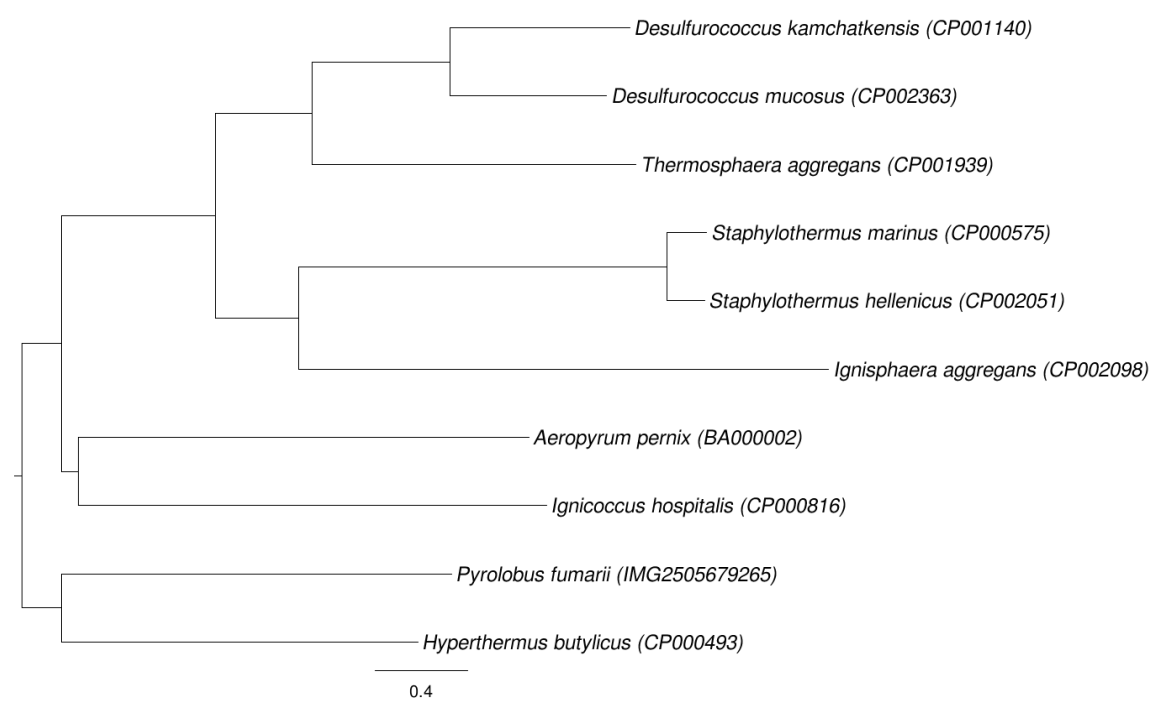

Figure 4. GGDC NJ tree inferred from the type strain genomes within the order Desulfurococcales.

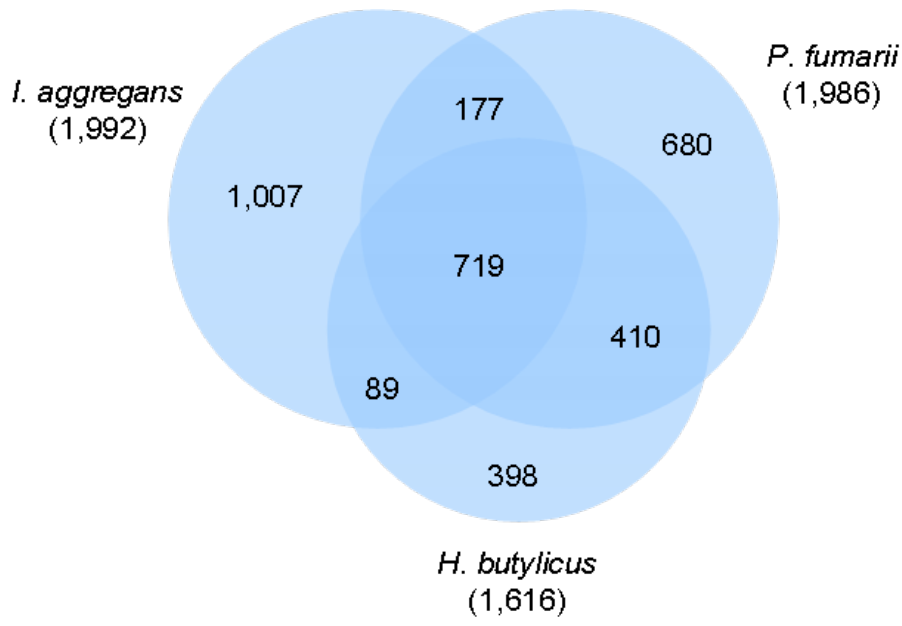

Figure 5. Venn diagram depicting the intersections of protein sets (total numbers in parentheses) of $P$. fumarii, I. aggregans and $H$. butylicus. 


\section{Acknowledgements}

This work was performed under the auspices of the US Department of Energy Office of Science, Biological and Environmental Research Program, and by the University of California, Lawrence Berkeley National Laboratory under contract No. DE-AC02-05CH11231, Lawrence Livermore National Laboratory under Contract No. DE-AC5207NA27344, and Los Alamos National Laboratory under

\section{References}

1. Blöchl E, Rachel R, Burggraf S, Hafenbradl D, Jannasch HW, Stetter KO. Pyrolobus fumarii, gen. and sp. nov., represents a novel group of archaea, extending the upper temperature limit for life to 113 degrees C. Extremophiles 1997; 1:14-21. $\underline{\text { PubMed doi:10.1007/s007920050010 }}$

2. Rainey FA, Oren A. 2006. Extremophiles. In: Rainey FA, Oren A (eds), Methods in Microbiology, vol. 35. Elsevier, New York.

3. Validation List No. 71. Validation of publication of new names and new combinations previously effectively published outside the IJSB. Int I Syst Bacteriol 1999; 49:1325-1326. doi:10.1099/00207713-49-4-1325

4. Kashefi K, Lovley DR. Extending the upper temperature limit for life. Science 2003; 301:934. PubMed doi:10.1126/science.1086823

5. Altschul SF, Gish W, Miller W, Myers EW, Lipman DJ. Bascic local alignment search tool. J Mol Biol 1990; 215:403-410.

6. DeSantis TZ, Hugenholtz $\mathrm{P}$, Larsen N, Rojas M, Brodie EL, Keller K, Huber T, Dalevi D, Hu P, Andersen GL. Greengenes, a chimera-checked $16 \mathrm{~S}$ rRNA gene database and workbench compatible with ARB. Appl Environ Microbiol 2006; 72:5069-5072. PubMed doi:10.1128/AEM.03006-05

7. Porter MF. An algorithm for suffix stripping. Program: electronic library and information systems 1980; 14:130-137.

8. Castresana J. Selection of conserved blocks from multiple alignments for their use in phylogenetic analysis. Mol Biol Evol 2000; 17:540-552. PubMed

9. Lee C, Grasso C, Sharlow MF. Multiple sequence alignment using partial order graphs. Bioinformatics 2002; 18:452-464. PubMed doi:10.1093/bioinformatics/18.3.452

10. Stamatakis A, Hoover P, Rougemont J. A rapid bootstrap algorithm for the RAxML web servers. contract No. DE-AC02-06NA25396, UT-Battelle, and Oak Ridge National Laboratory under contract DE-AC05000R22725, as well as German Research Foundation (DFG) INST 599/1-1 and SI 1352/1-2 and Thailand Research Fund Royal Golden Jubilee Ph.D. Program No. PHD/0019/2548' for MY.

Syst Biol 2008; 57:758-771. PubMed doi:10.1080/10635150802429642

11. Hess PN, De Moraes Russo CA. An empirical test of the midpoint rooting method. Biol J Linn Soc Lond 2007; 92:669-674. doi:10.1111/j.10958312.2007.00864.x

12. Pattengale ND, Alipour M, Bininda-Emonds ORP, Moret BME, Stamatakis A. How many bootstrap replicates are necessary? Lect Notes Comput Sci 2009; 5541:184-200. doi:10.1007/978-3-642$\underline{02008-7 \quad 13}$

13. Swofford DL. PAUP*: Phylogenetic Analysis Using Parsimony (*and Other Methods), Version 4.0 b10. Sinauer Associates, Sunderland, 2002.

14. Liolios K, Chen IM, Mavromatis K, Tavernarakis $\mathrm{N}$, Hugenholtz P, Markowitz VM, Kyrpides NC. The Genomes On Line Database (GOLD) in 2009: status of genomic and metagenomic projects and their associated metadata. Nucleic Acids Res 2010; 38:D346-D354. PubMed doi:10.1093/nar/gkp848

15. Ravin NV, Mardanov AV, Beletsky AV, Kublanov IV, Kolganova TV, Lebedinsky AV, Chernyh NA, Bonch-Osmolovskaya EA, Skryabin KG. Complete genome sequence of the anaerobic, proteindegradinghyperthermophilic crenarchaeon Desulfurococcus kamchatkensis. I Bacteriol 2009; 191:2371-2379. PubMed doi:10.1128//B.01525$\underline{08}$

16. Wirth R, Chertkov O, Held B, Lapidus A, Nolan M, Lucas S, Hammon N, Deshpande S, Cheng JF, Tapia R, et al. Complete genome sequence of Desulfurococcus mucosus type strain $\left(07 / 1^{\top}\right)$. Stand Genomic Sci 2011; 4:173-182. PubMed doi:10.4056/sigs.1644004

17. Spring $S$, Rachel R, Lapidus A, Davenport K, Tice $\mathrm{H}$, Copeland A, Cheng JF, Lucas S, Chen F, Nolan $M$, et al. Complete genome sequence of Thermosphaera aggregans type strain $\left(\mathrm{M} 11 \mathrm{TL}^{\mathrm{T}}\right)$. Stand Genomic Sci 2010; 2:245-259. PubMed doi:10.4056/sigs.821804 
Anderson et al.

18. Kawarabayasi $Y$, Hino $Y$, Horikawa $H$, Yamazaki S, Haikawa Y, Jin-no K, Takahashi M, Sekine M, Baba S, Ankai A, et al. Complete genome sequence of an aerobic hyper-thermophilic crenarchaeon, Aeropyrum pernix K1. DNA Res 1999; 6:83-101. PubMed doi:10.1093/dnares/6.2.83

19. Podar M, Anderson I, Makarova KS, Elkins JG, Ivanova N, Wall MA, Lykidis A, Mavromatis K, Sun $\mathrm{H}$, Hudson ME, et al. A genomic analysis of the archaeal system Ignicoccus hospitalisNanoarchaeum equitans. Genome Biol 2008; 9:R158. PubMed doi:10.1186/gb-2008-9-11-r158

20. Göker M, Held B, Lapidus A, Nolan M, Spring S, Yasawong M, Lucas S, Glavina Del Rio T, Tice H, Cheng JF, et al. Complete genome sequence of Ignisphaera aggregans type strain (AQ1.S1 $\left.{ }^{\mathrm{T}}\right)$. Stand Genomic Sci 2010; 3:66-75. PubMed $\underline{\text { doi:10.4056/sigs.1072907 }}$

21. Brügger $K$, Chen $L$, Stark $M$, Zibat $A$, Redder $P$, Ruepp A, Awayez M, She Q, Garrett RA, Klenk HP. The genome of Hyperthermus butylicus: a sulfur-reducing, peptide fermenting, neutrophilic crenarchaeote growing up to $108^{\circ} \mathrm{C}$. Archaea 2008; 2:127-135. PubMed doi:10.1155/2007/745987

22. Field D, Garrity G, Gray T, Morrison N, Selengut J, Sterk P, Tatusova T, Thomson N, Allen MJ, Angiuoli SV, et al. The minimum information about a genome sequence (MIGS) specification. Nat Biotechnol 2008; 26:541-547. PubMed doi:10.1038/nbt1360

23. Garrity G. NamesforLife. BrowserTool takes expertise out of the database and puts it right in the browser. Microbiol Today 2010; 37:9.

24. Woese CR, Kandler O, Wheelis ML. Towards a natural system of organisms: proposal for the domains Archaea, Bacteria, and Eucarya. Proc Natl Acad Sci USA 1990; 87:4576-4579. PubMed doi:10.1073/pnas.87.12.4576

25. Garrity GM, Holt JG. 2001. Phylum Al. Crenarchaeota phy. nov., In: Boone DR, Castenholz RW, Garrity GM (eds), Bergey's Manual of Systematic Bacteriology, 2nd ed, vol. 1. SpringerVerlag, New York.

26. Validation List No. 85. Validation of publication of new names and new combinations previously effectively published outside the IJSEM. Int J Syst Evol Microbiol 2002; 52:685-690. PubMed doi:10.1099/ijs.0.02358-0

27. Reysenbach AL. 2001. Class I. Thermoprotei class. nov., In: Boone DR, Castenholz RW, Garrity GM (eds), Bergey's Manual of Systematic Bac- teriology, 2nd ed, vol. 1. p. 169-210 SpringerVerlag, New York.

28. Huber H, Stetter O. 2001. Order II. Desulfurococcales ord. nov., In: Garrity GM, Boone DR, Castenholz RW (eds), Bergey's Manual of Systematic Bacteriology, 2nd ed, vol. 1. p. 179-180 Springer, New York.

29. Burggraf S, Huber H, Stetter KO. Reclassification of the crenarchaeal orders and families in accordance with $16 \mathrm{~S}$ rRNA sequence data. Int I Syst Bacteriol 1997; 47:657-660. doi:10.1099/00207713-47-3-657

30. BauA 2005. Classification of bacteria and archaea in risk groups. http://www.baua.de TRBA 466 p. 286.

31. Ashburner M, Ball CA, Blake JA, Botstein D, Butler H, Cherry JM, Davis AP, Dolinski K, Dwight SS, Eppig JT, et al. Gene Ontology: tool for the unification of biology. Nat Genet 2000; 25:25-29. PubMed doi:10.1038/75556

32. Huber H, Stetter KO. 2006. Archaea. Bacteria: Firmicutes, Actinomycetes, In: Dworkin M, FalkowS, Rosenberg E, Schleifer KH, Stackebrandt E (eds), The Prokaryotes. A Handbook on the Biology of Bacteria, 3rd ed, vol. 3. p. 106-114 Springer, New York.

33. Berg IA, Ramos-Vera WH, Petri A, Huber H, Fuchs G. Study of the distribution of autotrophic $\mathrm{CO}_{2}$ fixation cycles in Crenarchaeota. Microbiology 2010; 156:256-269. PubMed doi:10.1099/mic.0.034298-0

34. Huber $\mathrm{H}$, Gallenberger $\mathrm{M}$, Jahn $\mathrm{U}$, Eylert $\mathrm{E}$, Berg IA, Kockelkorn D, Eisenreich W, Fuchs G. A dicarboxylate/4-hydroxybutyrate autotrophic carbon assimilation cycle in the hyperthermophilic archaeum Ignicoccus hospitalis. Proc Natl Acad Sci USA 2008; 105:7851-7856. PubMed doi:10.1073/pnas.0801043105

35. Agris PF. The importance of being modified: roles of modified nucleosides and Mg2+ in RNA structure and function. Prog Nucleic Acid Res Mol Biol 1996; 53:79-129. PubMed doi:10.1016/S00796603(08)60143-9

36. Davis DR. 1998. Modification and editing of RNA. ASM Press, Washington.

37. Derrick WB, Horowitz J. Probing structural differences between native and in vitro transcribed Escherichia coli valine transfer RNA: evidence for stable base modification-dependent conformers. Nucleic Acids Res 1993; 21:4948-4953. PubMed doi:10.1093/nar/21.21.4948 
38. McCloskey JA, Liu XH, Crain PF, Bruenger E, Guymon R, Hashizume T, Stetter KO. Posttranscriptional modification of transfer RNA in the submarine hyperthermophile Pyrolobus fumarii. Nucleic Acids Symp Ser 2000; 44:267-268. PubMed

39. Sampson JR, Uhlenbeck OC. Biochemical and physical characterization of an unmodified yeast phenylalanine transfer RNA transcribed in vitro. Proc Natl Acad Sci USA 1988; 85:1033-1037. PubMed doi:10.1073/pnas.85.4.1033

40. Gonçalves LG, Lamosa P, Huber R, Santos H. Dimyo-inositol phosphate and novel UDP-sugars accumulate in the extreme hyperthermophile $P y$ rolobus fumarii. Extremophiles 2008; 12:383-389. PubMed doi:10.1007/s00792-008-0143-0

41. Klenk HP, Göker M. En route to a genome-based classification of Archaea and Bacteria? Syst Appl Microbiol 2010; 33:175-182. PubMed doi:10.1016/j.syapm.2010.03.003

42. Wu D, Hugenholtz P, Mavromatis K, Pukall R, Dalin E, Ivanova NN, Kunin V, Goodwin L, Wu $M$, Tindall BJ, et al. A phylogeny-driven genomic encyclopaedia of Bacteria and Archaea. Nature 2009; 462:1056-1060. PubMed doi:10.1038/nature08656

43. List of growth media used at DSMZ: http://www.dsmz.de/microorganisms/media list.p hp.

44. The DOE Joint Genome Institute. http://www.jgi.doe.gov.

45. Phrap and Phred for Windows. MacOS, Linux, and Unix. http://www.phrap.com.

46. Zerbino DR, Birney E. Velvet: algorithms for de novo short read assembly using de Bruijn graphs. Genome Res 2008; 18:821-829. PubMed doi:10.1101/gr.074492.107
47. Han C, Chain P. 2006. Finishing repeat regions automatically with Dupfinisher. In: Proceeding of the 2006 international conference on bioinformatics \& computational biology. Arabina HR, Valafar H (eds), CSREA Press. June 26-29, 2006: 141-146.

48. Lapidus A, LaButti K, Foster B, Lowry S, Trong S, Goltsman E. POLISHER: An effective tool for using ultra short reads in microbial genome assembly and finishing. AGBT, Marco Island, FL, 2008.

49. Hyatt D, Chen GL, Locascio PF, Land ML, Larimer FW, Hauser LJ. Prodigal: prokaryotic gene recognition and translation initiation site identification. BMC Bioinformatics 2010; 11:119. PubMed doi:10.1186/1471-2105-11-119

50. Pati A, Ivanova NN, Mikhailova N, Ovchinnikova G, Hooper SD, Lykidis A, Kyrpides NC. GenePRIMP: a gene prediction improvement pipeline for prokaryotic genomes. Nat Methods 2010; 7:455-457. PubMed doi:10.1038/nmeth.1457

51. Markowitz VM, Ivanova NN, Chen IMA, Chu K, Kyrpides NC. IMG ER: a system for microbial genome annotation expert review and curation. Bioinformatics 2009; 25:2271-2278. PubMed doi:10.1093/bioinformatics/btp393

52. Auch AF, Klenk HP, Göker M. Standard operating procedure for calculating genome-to-genome distances based on high-scoring segment pairs. Stand Genomic Sci 2010; 2:142-148. PubMed doi:10.4056/sigs.541628

53. Auch AF, von Jan M, Klenk HP, Göker M. Digital DNA-DNA hybridization for microbial species delineation by means of genome-to-genome sequence comparison. Stand Genomic Sci 2010; 2:117-134. PubMed doi:10.4056/sigs.531120

54. genome-to-genome distance calculator. http://ggdc.gbdp.org 